\title{
Article
}

Subscriber access provided by Universidad de Alicante

\section{A metabolomic approach to detect effects of salmon farming on wild saithe (Pollachius virens) populations}

Frutos C. Marhuenda Egea, Kilian Toledo-Guedes, Pablo SanchezJerez, Ricardo Ibanco-Cañete, Ingebrigt Uglem, and Bjorn-Steinar Saether

J. Agric. Food Chem., Just Accepted Manuscript • DOI: 10.1021/acs.jafc.5b04765 • Publication Date (Web): 24 Nov 2015

Downloaded from http://pubs.acs.org on November 30, 2015

\section{Just Accepted}

"Just Accepted" manuscripts have been peer-reviewed and accepted for publication. They are posted
online prior to technical editing, formatting for publication and author proofing. The American Chemical
Society provides "Just Accepted" as a free service to the research community to expedite the
dissemination of scientific material as soon as possible after acceptance. "Just Accepted" manuscripts
appear in full in PDF format accompanied by an HTML abstract. "Just Accepted" manuscripts have been
fully peer reviewed, but should not be considered the official version of record. They are accessible to all
readers and citable by the Digital Object Identifier (DOI@). "Just Accepted" is an optional service offered
to authors. Therefore, the "Just Accepted" Web site may not include all articles that will be published
in the journal. After a manuscript is technically edited and formatted, it will be removed from the "Just
Accepted" Web site and published as an ASAP article. Note that technical editing may introduce minor
changes to the manuscript text and/or graphics which could affect content, and all legal disclaimers
and ethical guidelines that apply to the journal pertain. ACS cannot be held responsible for errors
or consequences arising from the use of information contained in these "Just Accepted" manuscripts. 
1 A metabolomic approach to detect effects of salmon farming on wild saithe

Frutos C. Maruhenda Egea ${ }^{1, *}$, Kilian Toledo-Guedes ${ }^{2,3}$, Pablo Sanchez-Jerez ${ }^{2}$, Ricardo IbancoCañete $^{1}$, Ingebrit Uglem ${ }^{3}$, Bjørn-Steinar Saether ${ }^{4}$

6

$7 \quad{ }^{1}$ Department of Agrochemistry and Biochemistry, University of Alicante, 03080 Alicante, Spain.

$8 \quad{ }^{2}$ Department of Marine Science and Applied Biology, University of Alicante, 03080 Alicante, Spain.

$9 \quad{ }^{3}$ Norwegian Institute of Nature Research (NINA), Tungasletta 2, 7485 Trondheim, Norway

$10{ }^{4}$ Nofima AS, The Norwegian Institute of Food, Fisheries and Aquaculture Research, 9291 Tromsø, 11 Norway.

12 *Corresponding author: frutos@,ua.es. Telephone number: +34 965903400 (ext. 2063).

13

14 Keywords: aquafeed; fish populations; metabolites; aquaculture; NMR; chemometric. 


\section{ABSTRACT}

18 Metabolomics approach was used to analyze effects of salmon farming on wild saithe (Pollachius

19 virens) populations. Saithe fish were captured at two salmon farms and at two control locations

20 around the island Hitra, Norway. Changes in diet seem to drive changes in metabolic status of 21 fishes. The liver and muscle tissues, from the fishes captured around the farm, showed higher levels

22 of lactate and certain amino acids (glutamine, glutamate and alanine), and lower levels of glucose 23 and choline, than the fishes captured in the control locations, far of the farm locations. The higher

24 levels of lactate and amino acids could be related with the facility to obtain food around the farm 25 and the deficit in choline with the deficit of this nutrient in the salmon feed. At each location the 26 fish were captured with either benthic gillnets and automatic jigging machines, and this feature 27 showed also variations in different metabolites. 


\section{INTRODUCTION}

Marine aquaculture and fisheries share space and resources, which may involve both potential synergies and unwanted interactions between these two important industries ${ }^{1,2}$. In a context where worldwide aquaculture production is expected to grow, the development of tools to detect aquaculture-fisheries interactions is of particular relevance ${ }^{3}$. Increased understanding on those interactions are required to manage them properly, avoiding conflicts among users

One well-known consequence of salmon culture in coastal areas is the aggregation of wild fish in the vicinity of the farms, which feed on the non-consumed pellets from the fish cage ${ }^{4}$. Previous studies have detected compositional side-effects in the fatty acids profile due to this trophic subsidy $^{5}$ that may lead to alterations in the physiology and even the quality of wild fish targeted by artisanal fisheries $^{6}$.

The set of techniques used to assess the influence of a pellet diet in wild fish is usually costly and time-consuming (e.g. fatty acid profile, trace elements analysis ${ }^{7}$ ). Alternatively, small molecules (i.e. metabolites) identifiable by Nuclear Magnetic Resonance (NMR) can discriminate fish origin in different situations ${ }^{8}$, and may be a useful and cost effective tool to trail effects of aquaculture on wild fish. NMR spectroscopy is a multi-component detection technique that offers the opportunity to detect most of the mentioned molecules and study biological tissue ${ }^{9-11}$. Most NMR analysis are based on signals from proton $\left({ }^{1} \mathrm{H}\right)$ nuclei, which is the most sensitive NMR nucleus. Protons in different local chemical environments produce signals at slightly different NMR frequencies and can therefore be observed at different positions in the spectrum. This position, termed chemical shift, allows the identification of individual components in a sample. For a given signal, the area under the signal curve is proportional to the concentration of the compound that gives rise to the peak, allowing quantification of compounds in the samples. The spectra obtained from tissue extracts are better resolved and therefore allow a more precise assignment of peak identities. Based on the detailed information from extracts it is possible to obtain an optimal classification of the 
metabolic status of the fish in certain environment.

These techniques may have practical applications for the selection of specimens according to their qualitative and quantitative content of small molecules, which is of relevance for the nutritional value of fish ${ }^{12-19}$. Therefore, analyses of the small molecules, such as leucine, valine, carnitine, creatine, glucose or glycogen, may be used to discriminate individuals ${ }^{12}$. The small molecules have a potential to serve as markers to trace the history of the fish since the type and amount of metabolites is affected by physiological factors or stress prior to death. The latter would permit the possibility to examine the effect of the diet and classify the fish according to their biochemical composition.

Salmon farming is the largest aquaculture industry in Europe, with a production in 2014 of almost 1.3 million tons, which consumed more than 1.6 million tons of pelleted fish feed in Norway alone $^{13}$. Saithe (Pollachius virens) is one of the most important species for Norwegian local fisheries, are commonly attracted in large amounts to fish farms due to the abundance of lost salmon feed ${ }^{14}$. Consequently, the food quality of the saithe may be modified in farming intensive areas due to a switch from natural prey to a diet consisting of salmon pellets ${ }^{2}$. However, recent research indicates that the negative quality influence depends on the fishing gear used ${ }^{2,1522}$.

The present study aims to define the liability of metabolites, determined by NMR, for detecting the influence of salmon farming on wild fish physiology, by analysing muscle and liver composition of wild saithe using NMR spectroscopy. Fish were captured around fish farms and control areas, using two alternative fishing gear (gillnets and angling), in order to define the suitability of NMR for environmental management of marine aquaculture. 


\section{MATERIALS AND METHODS}

75

76

77

78

\subsection{Fish sample preparation}

Saithe were captured between the 19th and 21st of September of 2012 at two salmon farms and at two control locations ( $>5 \mathrm{~km}$ from the nearest farm) around the island Hitra, Norway $\left(63.603658^{\circ} \mathrm{N}\right.$ $/ 8.645661^{\circ} \mathrm{E}$ ) (Supporting Information, Figure S1). At each location the fish were captured with either benthic gillnets and automatic jigging machines $(n=8)$. Fish were randomly chosen, but gut content for each individual was analysed and hepatosomatic index calculated for avoiding incorrect treatment assignment. Average length ( \pm standard error; SE) and weight $( \pm \mathrm{SE})$ of farm-aggregated saithe ("Farm") were $65.9 \pm 1.6 \mathrm{~cm}$ and $3115.8 \pm 211.1 \mathrm{~g}$ respectively; whereas average length $( \pm \mathrm{SE})$ and weight $( \pm \mathrm{SE})$ of saithe captured far from salmon farming activity (“Control”) was $66.4 \pm 2.6 \mathrm{~cm}$ and $2475.6 \pm 261.8 \mathrm{~g}$ respectively. Muscle and liver tissue samples (around $6 \mathrm{~g}$ ) were collected from the captured fish and kept at $-80^{\circ} \mathrm{C}$ for further analysis. In order to obtain the polar metabolites for ${ }^{1}$ H NMR experiments, the frozen stored samples were extracted using perchloric acid method ${ }^{9}$.

\subsection{Chemicals}

$\mathrm{D}_{2} \mathrm{O}$ (99.9\% purity) from Aldrich (Steinheim, Germany); sodium 3-trimethylsilyl-propionate2,2,3,3,-d4 (TSP, 99\% purity) from Aldrich (Steinheim, Germany); perchloric acid 70\% (puriss p.a. ACS) from Fluka Chemicals BioChemika (Buchs, Switzerland); and potasium carbonate (puriss p.a. ACS) from Panreac (Spain).

\subsection{In vitro ${ }^{1}$ H NMR spectroscopy}

All NMR experiments were performed on a Bruker Avance $400 \mathrm{MHz}$ equipped with a $5 \mathrm{~mm}{ }^{1} \mathrm{H}$ $\mathrm{BB}-{ }^{13} \mathrm{C}$ TBI probe with an actively shielded Z-gradient. ${ }^{1} \mathrm{D}$ solution state ${ }^{1} \mathrm{H}$ NMR experiments were acquired with a recycle delay of 2 s, 32.768 time domain points and with $2.556 \mathrm{~s}$ of acquisition time. The number of scans was 2253. Spectra were apodized by multiplication with an 
exponential decay producing a $0.3 \mathrm{~Hz}$ line broadening in the transformed spectrum. Direct ${ }^{1} \mathrm{H}$ NMR was performed using SPR-W5-WATERGATE ${ }^{16}$. Twelve ppm and -2 ppm and were outside the spectral window. The ${ }^{1} \mathrm{H}$ NMR spectra were reduced to ASCII files using custom-written ProMetab software (version 2.1) ) $^{17}$ and peak alignment using $i$ coshift (version 1.0; available at www.models.kvl.dk) ${ }^{18}$. All ${ }^{1} \mathrm{H}$ NMR spectra processing have been performed in MATLAB (The MathWorks, Natick, MA) using a AMD Turion X2, 2.20GHz processor with 4GB of RAM. Highresolution MR spectra of perchloric acid extracts from liver and muscle were first examined to provide detailed information about water soluble components ${ }^{9}$. Identification of individual components for muscle and liver was done by comparison to published values of chemical shifts, knowledge of the biochemical composition of fish skeletal muscle and liver and the identification of signals was obtained from 2D NMR spectra ${ }^{9,10,12}$. The assignment of the different resonances was listed in Table 1. Hypoxanthine, a molecule which is a good indicator for tissue freshness, was not detected in the ${ }^{1} \mathrm{H}$ NMR spectra.

\subsection{Chemometric analysis and experimental design.}

For the statistical analysis of spectroscopy data we performed a peak alignment ${ }^{18}$. When the peaks were aligned, robust principal components analysis (robust PCA) ${ }^{19}$ and partial least square with linear discriminant analysis (PLS-LDA) ${ }^{20}$ were performed. MATLAB version 6.5 from MathWorks was used for the calculations. Robust PCA was carried out using the LIBRA toolbox ${ }^{19}$ and PLSLDA was carried out using the plslda toolbox ${ }^{20}$. Two fixed factors were considered for statistical analysis: influence of aquaculture, with two treatments (Farm and Control) and fishing gear, also with two treatments (gillnet and jigging).

In a supervised method, such as PLS-LDA, the most common approach is to select a number of the data for to make a mathematical model. This model can be used for the prediction of new independent samples. The independent samples used for to validate the model are samples excluded in the construction of the mathematical model. With our ${ }^{1} \mathrm{H}$ NMR spectra for the different samples, 
122 we made PLS-LDA models. Every model was made with all samples less one. In every case, the

123 model was validated with the sample excluded. In other words, we made so many models as

124 samples, but in every model was excluded one sample. This approach had two advantages: we can

125 detect quickly samples wrong classified and all models are very similar. We our data, all samples

126 were classified in the correct group when any of the two factors were considered (influence of

127 aquaculture, with two treatments (Farm and Control) or fishing gear, also with two treatments

128 (gillnet and jigging)).

129 


\section{RESULTS}

131 The ${ }^{1} \mathrm{H}$ NMR metabolic profile spectra aqueous liver extract (Supporting Information, Figure S2)

132 showed that the profile was dominated by different signals assigned to metabolites such as glucose,

133 glycerol, lactate, alanine, choline and taurine. Other metabolites, such as acetate and several amino

134 acids were also assigned (glutamine, glutamate, leucine, valine and isoleucine). Signals in the

135 aromatic region (below $6 \mathrm{ppm}$ ) were assigned to the nucleosides/nucleobases, adenosine, inosine,

136 uridine, uracil and aromatic amino acid. In the case of muscle, the 1H NMR spectra were dominated

137 by signals from lactate, anserine, choline, creatine/phosphocreatine (Supporting Information, Figure

138 S3). Signals from taurine, amino-acids (alanine, glycine, glutamine, glutamate, histidine, leucine,

139 isoleucine, lysine, and valine), carbohydrates and nucleosides or nucleotides (adenosine, ATP) were

140 also observed.

141 In order to analyze the ${ }^{1} \mathrm{H}$ NMR metabolic profile spectra, we used an unsupervised chemometric

142 method such as robust $\mathrm{PCA}^{19}$. The scores plots from liver tissues samples displayed a good

143 separation between the Farm and Control fishes (Figures 1.A and 1.B). The separation between the

144 samples was determined by the loadings from PC2 (Figure 1.D). The loadings were not real data,

145 but they can be interpreted as such in order to evaluate the importance of the different metabolites

146 in the distribution of the samples in the scores plots. The loadings from PC2 (Figure 1.D) showed

147 that in the liver tissue, the Farm fishes had higher lactate, amino acids (glutamine, glutamate and

148 lysine) and carnitine concentrations and lower taurine concentrations than the Control fishes. The

149 loadings from PC1 could be more related to the fish capture method (gillnet or jigging) (Figure

150 1.C). The loadings from PC1 indicated that the fish captured with gillnet had higher concentrations

151 of alanine and lactate, and lower concentrations of glucose, glycerol, carnitine and choline (Figure

152 1.C).With muscle tissue, the situation was very similar when the ${ }^{1} \mathrm{H}$ NMR spectra were analysed by

153 robust PCA. The loadings from PC1 determined the distribution of the samples in the scores plots

154 (Figure 2). The loadings from PC1 displayed that the Farm fishes had higher concentration of 
155 lactate and alanine, and lower concentration of choline than the Control fishes (Figure 2.C). The

156 influence of the fishing method on the metabolomic profile was less clear in the ${ }^{1} \mathrm{H}$ NMR data from

157 muscle tissue than in liver tissue. The liver is the central tissue in the energetic metabolism and it is

158 an organ that quickly adapts to situations of stress, as it would be the catch of fish. However, the

159 metabolic changes in the muscle were lower because this tissue would need more time to adapt to

160 situations of stress.

161 The results from a supervised multivariate method such as PLS-LDA ${ }^{20}$ showed that ${ }^{1} \mathrm{H}$ NMR data

162 was able to discriminate powerfully between Farm and Control fishes (Figure 3), using the

163 approach described in Materials and Methods section. The liver tissue from Farm fish had a higher

164 concentration of lactate, amino acids (alanine, glutamine and glutamate) and carnitine (loadings

165 from $\mathrm{C} 1$ ) and lower concentration of taurine than the liver tissues from Control fishes. When the

166 capture fish method was considered as the metabolomic variable (gillnet or jigging), the fish captured with gillnet had higher concentration of lactate and alanine, and lower concentration of glucose and glycerol than the fishes captured with jigging (Figure 4).

169

170

171

172

173

174

175

176

177

178

If the ${ }^{1} \mathrm{H}$ NMR spectra from muscle tissue were analysed by PLS-LDA, between Farm and Control fishes the discrimination power was also very high (Figure 5). When the proximity of the farms was considered in the classification, the lactate and amino acids (glutamine, glutamate and alanine) concentration were higher in muscle tissues from Farm fishes than in muscle tissues from Control fishes (Figure 6). However, the muscle tissues from Control fishes displayed higher concentration in choline and taurine than Farm fishes. With PLS-LDA analysis of ${ }^{1} \mathrm{H}$ NMR spectra, there was a very good classification of the muscle tissues samples when the fishing method was considered as metabolomic variable (Figure 6). 
179

180

181

182

183

184

185

186

187

188

189

190

191

192

193

194

195

196

197

198

199

200

201

202

203

\section{DISCUSSION}

Salmon farming affected metabolic composition of main tissues, such as muscle and liver, of wild fish aggregated to fish farms, most likely because of the fish feed eaten by the wild fish. ${ }^{1} \mathrm{H}$ NMR proved to be a valuable and cost-effective tool for monitoring aquaculture-wild fish interactions by metabolomic changes. Saithe, in the same way as other species that use fish farms as an artificial trophic niche ${ }^{21}$, experience metabolic changes, which could have negative or even positive physiological effects. Additionally to fish farming influence, the fishing technique also affected the physiology of the fish due to the differential stress caused by the different fishing gears.

A particular effect of fish farming is that the ${ }^{1} \mathrm{H}$ NMR profiles from liver and muscle tissues of Farm fishes showed less dispersion in the score plots compared to the Controls. The latter is likely due to the prevalence of salmon feed as trophic resource, which is quite homogeneous with respect to nutritional content compared to natural prey. Saithe aggregated to salmon farms normally obtain a considerable proportion of their food from lost pellets or perhaps also salmon faeces. It has been shown that up to $45 \%$ of the diet originates from pellets and/or faeces ${ }^{22}$. Conversely, in a natural sea environment, the diet is expected to be more diverse ${ }^{23}$, which is reflected in a more variable metabolite profile.

It is noticeable that, although total length of Control and Farm individuals was similar, the fish weight was larger in the latter group, which results in a higher condition index for aggregated fishes. This effect is directly linked to the consume of high fat content feed, as it has been demonstrate for gadoids associated with salmon farms ${ }^{14}$. This increase in fat content could be driving the observed intergroup differences in the metabolites profile, especially in liver tissue as most of the lipid metabolism takes place in the $\operatorname{liver}^{24}$. Saithe is a gadoid, and this family accumulate fat in the liver as energy reservoir, and high lipid content salmon feed may contribute accumulation of fat in the liver. The liver is the centre of the energetic metabolism in the organism, and it controls and buffers the variation in the food intake, affecting metabolite composition 
204 The higher levels of different metabolites such as lactate and amino acid (glutamine, glutamate and 205 alanine) found in Farm fish, both in liver and muscle tissues, are residues from anaerobic lactic 206 fermentation. This anaerobic lactic fermentation is conditioned by the low oxygen transport to the 207 muscle tissue and can be related to fish mobility and fitness ${ }^{25}$, both being supposed to be higher in 208 those fish not associated to farm facilities (i.e. Control fish). This is supported by tagging studies, which show that saithe have long residence times around fish farms with repeated movements 210 between nearby facilities ${ }^{26}$. Therefore, the Farm fish could be having lower oxygen transport to the 211 muscle and, as a consequence, higher lactate and alanine concentrations in its metabolism ${ }^{25}$. The 212 lactate produced in the muscle tissue should be translated to the liver (Cori cycle) ${ }^{27}$. In the liver, the 213 lactate can be transformed into glucose by the gluconeogenesis pathway ${ }^{27}$. The Cori cycle could explain the increased lactate level in the liver and muscle tissues in Farm fishes. In the same way, in the muscle tissue, different proteins would be degraded in order to obtain energy. The carbon skeleton of the amino acid would be used in the energy pathways, but the amino group should be translated to the liver as glutamine and alanine ${ }^{27}$. The glutamate is the more important intermediate 218 in the deamination process of the amino $\operatorname{acid}^{27}$. In addition, the glutamine and glutamate are 219 intermediate in the urea cycle in the $\operatorname{liver}^{27}$. In the liver tissue, the Farm fish had higher level of 220 carnitine. This molecule is the acyl group's carrier to the mitochondrial matrix for the $\beta$-oxidation ${ }^{27}$, 221 which is the source of energy for the gluconeogenesis ${ }^{27}$. The energy necessity was probably higher in the Farm fish by the high lactate and alanine levels that should be transformed in glucose. In muscle tissue, as explained above, the highest levels of lactate and alanine was found in Farm fish. However, the Control fish had higher levels of choline than the Farm fish. Choline has several important metabolic roles. The neurotransmiter acetylcholine is a derivate to the choline, such as the phosphatidylcholine (lecithin). Phosphatidylcholine has structural functions in membranes and in the lipid transport. Also, choline is an important methyl donor for methylation reactions ${ }^{27}$. Choline can be synthesized in the body from methionine or cysteine ${ }^{27}$. The synthesis in the body is not 
230 produced by a methionine scarcity in the fish diets ${ }^{28}$. The fish feeds can be deficient in choline 231 because the soybean seeds are rich in choline, but this is lost during the processing (i.e. the fat of the 232 oilseed is removed before preparation of the feed, and the choline is also removed with the rest of 233 lipids). For this reason the salmon feed is supplemented with choline chloride ${ }^{28}$, but this 234 supplementation could be insufficient for the wild fish population around the farm. In the same way, 235 it is important to consider that the proteins with animal origin are richer in methionine than the 236 protein from plants. Gadoids are carnivorous with a high trophic level and are eating mainly fish, 237 crustaceans, echinoderms, and polychaetes ${ }^{14,23}$, and this natural diet should reduce diet deficient.

238 The lactic fermentation produces only two ATP molecules per glucose molecule. It is a very 239 inefficient metabolic process, and it produces principally lactic acid, because it is an anaerobic 240 process. The accumulation of lactic acid decreases the $\mathrm{pH}$ of the muscle tissue ${ }^{29}$. Moreover, lactic 241 acid concentration is related to the glycogen stored in the living muscle, since the glucose of the 242 glycogen is the substrate in the glycolysis. The glycolysis is the first metabolic pathway in the lactic 243 fermentation. The level of the glycogen in the muscle is determined by the nutritional status of the 244 fish. Probably, Farm fish can store more glycogen with a pellet diet, and therefore the lactic acid in 245 the muscle was higher than that the Control fish. A subsequent decrease in the $\mathrm{pH}$ of the muscle 246 could have modified the physical properties of the tissue, since certain muscle proteins may have 247 lost their water-holding capacity by a partial denaturation ${ }^{30}$. This fact should have an effect on flesh 248 quality for human consumers because a change in the surface charge of the muscle proteins, due to 249 a presumable lower $\mathrm{pH}$, enhances the water loss, and this feature determines the muscle toughness 250 and a lower quality of the muscle ${ }^{30}$.

251 The observed differences in tissue composition due to the fishing gear are in concordance with 252 other studies, which have pointed, ultimately, to changes in the quality of flesh depending on the 253 capture method ${ }^{15}$. In extensive cases, those fishing methods involving exhaustion of fish because a 254 slow death (e.g. trawl, trammel and gill nets) provide lower quality fish when compared to 
255 techniques with a quick sacrifice and fish bleeding (e.g. longline, jigging). Quality is intimately 256 related to the metabolism exhibited by fish when it is captured by a certain fishing method, but 257 other factors as handling and storage are important driving forces of fish quality ${ }^{31}$. The fishing gear 258 will influence the levels of pre-capture stress, and the direct relation between this stress and the 259 lactic acid production in the muscle is known for saithe ${ }^{29}$. Other key factor altering final 260 metabolomic profile and flesh quality could be the bleeding of the fish, because the post-mortem 261 lactic acid accumulation is significantly reduced when the fish is properly bled ${ }^{32}$. The excess of fat 262 due to a diet consisting of salmon pellets could also affect flesh quality depending on fish capture 263 technique and handling ${ }^{33}$.

264 Salmon farming aggregate large numbers of gadoids most likely due to the abundance of lost 265 salmon feed ${ }^{4}, 14$. Therefore, salmon farming seem to influence metabolic profiles of wild fish but 266 other factors as capture method should also be considered when explaining metabolomics profile 267 changes. Further studies are needed to ascertain physiological and ecological consequences of a 268 pellet diet for wild fish assemblages and the interaction with other factors such as fish migrations, 269 physiological seasonal changes as reproduction, fishing gear and fish handling.

\section{CONCLUSIONS}

271 Salmon farming interact with wild fish populations in a complex way ${ }^{2}$. Changes in diet seem to 272 drive changes in metabolic status of important tissues such as liver and muscle in wild fish 273 aggregated at fish farms. These changes could also be affected by fishing techniques. Using a 274 metabolomic approach by ${ }^{1} \mathrm{H}$ NMR, it is possible to classify the individual depending on farming 275 influence and fishing gear, hence this technique could be useful for monitoring influence of fish 276 farming on local fisheries and also, the metabolomic results could explain potential variations in the 277 fillet quality. 


\section{ACKNOWLEDGMENT}

280

This research was funded by the Norwegian Seafood Research Fund through the project 'Evaluation of actions to promote sustainable coexistence between salmon culture and coastal fisheries, ProCoEx’ (Project number: 900772). Kilian Toledo-Guedes was supported by a grant from Iceland, Liechtenstein and Norway through the EEA Financial Mechanism. Operated by Universidad Complutense de Madrid. The authors want to thank Dr. E. Lorenzo for the technical support.

\section{FUNDING SOURCES}

The work was funded by the Norwegian Seafood Research Fund through the project 'Evaluation of actions to promote sustainable coexistence between salmon culture and coastal fisheries, ProCoEx' (Project number: 900772).

Kilian Toledo-Guedes was supported by a grant from Iceland, Liechtenstein and Norway through the EEA Financial Mechanism. Operated by Universidad Complutense de Madrid.

Supporting Information. Figures with the study area around Hitra Island, Norway, 1H NMR spectrum of perchloric acid extract from liver and muscle of wild saithe (Pollachius virens). This material is available free of charge via the Internet at http://pubs.acs.org. 


\section{REFERENCES}

302 1. Mikkelsen, O.; van den Berg, C.; Schroder, K., Determination of labile iron at low nmol L-1

303 levels in estuarine and coastal waters by anodic stripping voltammetry. Electroanalysis 2006, 18 304 (1), 35-43.

305 2. Uglem, I.; Karlsen, O.; Sanchez-Jerez, P.; Saether, B., Impacts of wild fishes attracted to 306 open-cage salmonid farms in Norway. Aquaculture Environment Interactions 2014, 6 (1), 91-103.

307 3. Cataudella, S.; Massa, F.; Crosetti, D., Interaction Between Aquaculture and Capture 308 Fisheries: a methodological perspective. FAO: Rome, 2005; Vol. N. 78, p 229.

309 4. Dempster, T.; Uglem, I.; Sanchez-Jerez, P.; Fernandez-Jover, D.; Bayle-Sempere, J.; Nilsen, 310 R.; Bjorn, P., Coastal salmon farms attract large and persistent aggregations of wild fish: an 311 ecosystem effect. Marine Ecology Progress Series 2009, 385, 1-14.

312 5. Fernandez-Jover, D.; Martinez-Rubio, L.; Sanchez-Jerez, P.; Bayle-Sempere, J.; Jimenez, J.; 313 Lopez, F.; Bjorn, P.; Uglem, I.; Dempster, T., Waste feed from coastal fish farms: A trophic subsidy 314 with compositional side-effects for wild gadoids. Estuarine Coastal and Shelf Science 2011, 91 (4), $315 \quad 559-568$.

316 6. Ottera, H.; Karlsen, O.; Slinde, E.; Olsen, R., Quality of wild-captured saithe (Pollachius 317 virens L.) fed formulated diets for 8 months. Aquaculture Research 2009, 40 (11), 1310-1319.

318 7. Arechavala-Lopez, P.; Fernandez-Jover, D.; Black, K.; Ladoukakis, E.; Bayle-Sempere, J.; 319 Sanchez-Jerez, P.; Dempster, T., Differentiating the wild or farmed origin of Mediterranean fish: a 320 review of tools for sea bream and sea bass. Reviews in Aquaculture 2013, 5 (3), 137-157.

321 8. Arechavala-Lopez, P.; Uglem, I.; Fernandez-Jover, D.; Bayle-Sempere, J.; Sanchez-Jerez, P., 322 Immediate post-escape behaviour of farmed seabass (Dicentrarchus labrax L.) in the Mediterranean 323 Sea. Journal of Applied Ichthyology 2011, 27 (6), 1375-1378.

324 9. Gribbestad, I.; Aursand, M.; Martinez, I., High-resolution 1H magnetic resonance 
325 spectroscopy of whole fish, fillets and extracts of farmed Atlantic salmon (Salmo salar) for quality 326 assessment and compositional analyses. Aquaculture 2005, 250 (1-2), 445-457.

327 10. Martinez, I.; Bathen, T.; Standal, I.; Halvorsen, J.; Aursand, M.; Gribbestad, I.; Axelson, D., 328 Bioactive compounds in cod (Gadus morhua) products and suitability of H-1 NMR metabolite 329 profiling for classification of the products using multivariate data analyses. Journal of Agricultural 330 and Food Chemistry 2005, 53 (17), 6889-6895.

331 11. Viant, M.; Bundy, J.; Pincetich, C.; de Ropp, J.; Tjeerdema, R., NMR-derived 332 developmental metabolic trajectories: an approach for visualizing the toxic actions of 333 trichloroethylene during embryogenesis. Metabolomics 2005, 1 (2), 149-158.

334 12. Wagner, L.; Trattner, S.; Pickova, J.; Gomez-Requeni, P.; Moazzami, A., H-1 NMR-based 335 metabolomics studies on the effect of sesamin in Atlantic salmon (Salmo salar). Food Chemistry $336 \quad \mathbf{2 0 1 4}, 147,98-105$.

337 13. Norwegian Directorate of Fisheries. 2015.

338 14. Dempster, T.; Sanchez-Jerez, P.; Fernandez-Jover, D.; Bayle-Sempere, J.; Nilsen, R.; Bjorn, 339 P.; Uglem, I., Proxy Measures of Fitness Suggest Coastal Fish Farms Can Act as Population Sources 340 and Not Ecological Traps for Wild Gadoid Fish. Plos One 2011, 6 (1).

341 15. Rotabakk, B.; Skipnes, D.; Akse, L.; Birkeland, S., Quality assessment of Atlantic cod 342 (Gadus morhua) caught by longlining and trawling at the same time and location. Fisheries 343 Research 2011, $112(1-2), 44-51$.

344 16. Lam, B.; Simpson, A., Direct H-1 NMR spectroscopy of dissolved organic matter in natural 345 waters. Analyst 2008, 133 (2), 263-269.

346 17. Viant, M., Improved methods for the acquisition and interpretation of NMR metabolomic 347 data. Biochemical and Biophysical Research Communications 2003, 310 (3), 943-948.

348 18. Savorani, F.; Tomasi, G.; Engelsen, S., icoshift: A versatile tool for the rapid alignment of 1D 
349

350

351

352

353

354

355

356

357

358

359

360

361

362

363

364

365

366

367

NMR spectra. Journal of Magnetic Resonance 2010, 202 (2), 190-202.

19. Verboven, S.; Hubert, M., LIBRA: a MATLAB library for robust analysis. Chemometrics and Intelligent Laboratory Systems 2005, 75 (2), 127-136.

20. Li, H.; Liang, Y.; Xu, Q.; Cao, D., Key wavelengths screening using competitive adaptive reweighted sampling method for multivariate calibration. Anal Chim Acta 2009, 648 (1), 77-84.

21. Sanchez-Jerez, P.; Fernandez-Jover, D.; Bayle-Sempere, J.; Valle, C.; Dempster, T.; Tuya, F.; Juanes, F., Interactions between bluefish Pomatomus saltatrix (L.) and coastal sea-cage farms in the Mediterranean Sea. Aquaculture 2008, 282 (1-4), 61-67.

22. Skog, T.; Hylland, K.; Torstensen, B.; Berntssen, M., Salmon farming affects the fatty acid composition and taste of wild saithe Pollachius virens L. Aquaculture Research 2003, 34 (12), 9991007.

23. Homrum, E.; Hansen, B.; Steingrund, P.; Hatun, H., Growth, maturation, diet and distribution of saithe (Pollachius virens) in Faroese waters (NE Atlantic). Marine Biology Research 2012, 8 (3), 246-254.

24. Tocher, D.; Castell, J.; Dick, J.; Sargent, J., Effects of Salinity on the Fatty-Acid Compositions of Total Lipid and Individual Glycerophospholipid Classes of Atlantic Salmon (Salmo-Salar) and Turbot (Scophthalmus-Maximus) Cells In Culture. Fish Physiology and Biochemistry 1995, 14 (2), 125-137.

25. Moyes, C. D.; West, T. G., Exercise metabolism of fish. In Biochemistry and Molecular Biology of Fishes, W., H. P.; P., M. T., Eds. Elsevier Science Amsterdam, 1995; Vol. 4, pp 367-392.

26. Uglem, I.; Dempster, T.; Bjorn, P.; Sanchez-Jerez, P.; Okland, F., High connectivity of salmon farms revealed by aggregation, residence and repeated movements of wild fish among farms. Marine Ecology Progress Series 2009, 384, 251-260.

27. Nelson, D.; Michael, C., Lehninger Principles of Biochemitry. 2014; p 1198. 
373 28. Lovell, T., Nutrition and feeding of fish. 2. ed.; Kluwer Academic Publishers: Boston, Mass., 374 1998; p ix, 267 s.

375 29. Roth, B.; Rotabakk, B., Stress associated with commercial longlining and recreational 376 fishing of saithe (Pollachius virens) and the subsequent effect on blood gases and chemistry. 377 Fisheries Research 2012, 115, 110-114.

378 30. Love, R., Variability in Atlantic Cod (Gadus-Morhua) From Northeast Atlantic - Review Of 379 Seasonal and Environmental Influences on Various Attributes of Flesh. Journal of the Fisheries 380 Research Board of Canada 1975, 32 (12), 2333-2342.

381 31. Esaiassen, M.; Nilsen, H.; Joensen, S.; Skjerdal, T.; Carlehog, M.; Eilertsen, G.; Gundersen, 382 B.; Elvevoll, E., Effects of catching methods on quality changes during storage of cod (Gadus 383 morhua). Lebensmittel-Wissenschaft Und-Technologie-Food Science and Technology 2004, 37 (6), $384 \quad 643-648$.

385 32. Chiba, A.; Hamaguchi, M.; Kosaka, M.; Tokuno, T.; Asai, T.; Chichibu, S., Quality 386 Evaluation of Fish Meat by Phosphorus-31-Nuclear Magnetic-Resonance. Journal of Food Science 387 1991, $56(3), 660-664$.

388 33. Regost, C.; Arzel, J.; Cardinal, M.; Laroche, M.; Kaushik, S., Fat deposition and flesh 389 quality in seawater reared, triploid brown trout (Salmo trutta) as affected by dietary fat levels and 390 starvation. Aquaculture 2001, 193 (3-4), 325-345. 
394 Table 1. Resonance assignments with ${ }^{1} \mathrm{H}$ chemical shifts of metabolites identified in NMR spectra of 395 perchloric acid extract from tissues of wild saithe (Pollachius virens).

\begin{tabular}{|c|c|c|c|}
\hline Compound & Proton & Multiplicity & $\delta{ }^{1} \mathrm{H}$ \\
\hline Leucine/Iseleucine & $-\mathrm{CH}_{3}$ & $\mathrm{~d}$ & 0.97 \\
\hline Valine & $-\mathrm{CH}_{3}$ & d & 1.19 \\
\hline Lactate & $-\mathrm{CH}_{3}$ & $\mathrm{~d}$ & 1.34 \\
\hline Alanine & $-\mathrm{CH}_{3}$ & d & 1.49 \\
\hline Lysine & $-\mathrm{CH}_{2}$ & $\mathrm{~m}$ & 1.73 \\
\hline Acetate & $-\mathrm{CH}_{3}$ & $\mathrm{~s}$ & 1.92 \\
\hline Glutamine/glutamate & $-\mathrm{CH}_{3}$ & $\mathrm{~m}$ & 2.14 \\
\hline Glutamate & $-\mathrm{CH}_{2}$ & $\mathrm{~m}$ & 2.35 \\
\hline Glutamine & $-\mathrm{CH}_{2}$ & $\mathrm{~m}$ & 2.43 \\
\hline Anserine & $-\mathrm{CH}_{3}$ & & 2.73 \\
\hline Creatine & $-\mathrm{NCH}_{3}$ & $\mathrm{~s}$ & 3.04 \\
\hline Choline & $-\mathrm{NCH}_{3}$ & $\mathrm{~s}$ & 3.13 \\
\hline Phosphocholine & $-\mathrm{N}\left(\mathrm{CH}_{3}\right)_{3}$ & $\mathrm{~s}$ & 3.21 \\
\hline$\beta$-Glucose & $-\mathrm{C} 2 \mathrm{H}$, ring & $\mathrm{dd}$ & 3.22 \\
\hline Carnitine & $-\mathrm{N}\left(\mathrm{CH}_{3}\right)_{3}$ & $\mathrm{~s}$ & 3.26 \\
\hline Taurine & $-\mathrm{S}-\mathrm{CH}_{2}$ & $\mathrm{t}$ & 3.42 \\
\hline$\beta$-Glucose & $-\mathrm{C} 5 \mathrm{H}$, ring & ddd & 3.47 \\
\hline$\beta$-Glucose & $-\mathrm{C} 3 \mathrm{H}$, ring & $\mathrm{t}$ & 3.49 \\
\hline Choline & $\beta \mathrm{H}$ & $\mathrm{m}$ & 3.51 \\
\hline Glycine & $\alpha \mathrm{H}$ & $\mathrm{s}$ & 3.58 \\
\hline Glycerol & $1,3 \mathrm{H} \beta$ & $\mathrm{dd}$ & 3.64 \\
\hline Glycerolphosphocholine & $\beta \mathrm{H}$ & $\mathrm{dd}$ & 3.68 \\
\hline Anserine & $-\mathrm{NCH}_{3}$ & & 3.69 \\
\hline$\alpha$-Glucose & $-\mathrm{C} 3 \mathrm{H}$, ring & $\mathrm{t}$ & 3.70 \\
\hline$\beta$-Glucose & -C6H, ring & $\mathrm{dd}$ & 3.70 \\
\hline Aspartic Acid & $\alpha \mathrm{H}$ & $\mathrm{dd}$ & 3.78 \\
\hline$\alpha$-Glucose & $-\mathrm{C} 5 \mathrm{H}$, ring & $\mathrm{m}$ & 3.84 \\
\hline$\beta$-Glucose & $-\mathrm{C} 6 \mathrm{H}$, ring & $\mathrm{dd}$ & 3.89 \\
\hline Creatine & $-\mathrm{CH}_{2}$ & $\mathrm{~s}$ & 3.93 \\
\hline Lactate & $-\mathrm{CH}$ & $\mathrm{q}$ & 4.11 \\
\hline Adenosine & $\mathrm{H} 1$ & & 6.09 \\
\hline Histidine (in anserine) & $-\mathrm{C} 4 \mathrm{H}$, ring & S & 6.88 \\
\hline Tyrosine & $-\mathrm{C} 3,5 \mathrm{H}$ ring & $\mathrm{m}$ & 6.91 \\
\hline Tyrosine & $-\mathrm{C} 2,6 \mathrm{H}$ ring & $\mathrm{m}$ & 7.19 \\
\hline Histidine (in anserine) & $-\mathrm{C} 2 \mathrm{H}$, ring & $\mathrm{s}$ & 8.23 \\
\hline Formate & $-\mathrm{CH}$ & $\mathrm{s}$ & 8.52 \\
\hline
\end{tabular}


398

399

400

401

402

403

404

405

406

407

408

409

410

411

412

413

414

415

416

417

418

419

420

Figure 1. Robust PCA analysis performed on ${ }^{1} \mathrm{H}$ NMR spectra from liver tissues of wild saithe (Pollachius virens). A) and B). Scores plots from PC. (ם) Control with angling; ( $\mathbf{\Delta})$ Control with gillnet, ( $\square$ ) Farm with angling; ( $\Delta$ ) Farm with gillnet. C and D) Loadings plots from PCs. The first principal component (PC1) was described by $33.70 \%$, the second principal component (PC2) by $25.59 \%$, and the third principal component (PC3) by $11.28 \%$ of the variations .

Figure 2. Robust PCA analysis performed on ${ }^{1} \mathrm{H}$ NMR spectra from muscle tissues of wild saithe (Pollachius virens). A and B) Scores plots from PC. (ם) Control with angling; ( $\mathbf{\Delta})$ Control with gillnet, $(\square)$ Farm with angling; ( $\Delta$ ) Farm with gillnet. C and D) Loadings plots from PCs. The first principal component (PC1) was described by $85.74 \%$, the second principal component (PC2) by $4.80 \%$, and the third principal component (PC3) by $3.52 \%$ of the variations.

Figure 3. PLS-LDA performed on ${ }^{1} \mathrm{H}$ NMR spectra from liver tissues of wild saithe (Pollachius virens) using the proximity to the farm as classification criteria. A and B) Scores plots from PLSLDA. ( $\square$ ) Control with angling; ( $\boldsymbol{\Delta}$ ) Control with gillnet, ( $\square$ ) Farm with angling; ( $\Delta$ ) Farm with gillnet. C and D) Loadings plots from PLS-DA. The first component (C1) was described by $83.81 \%$, the second component (C2) by $6.22 \%$, and the third component (C3) by $5.87 \%$ of the variations.

Figure 4. PLS-LDA performed on ${ }^{1} \mathrm{H}$ NMR spectra from liver tissues of wild saithe (Pollachius virens) using the fishing method as classification criteria. A and B) Scores plots from PLS-LDA. (ם) Control with angling; (A) Control with gillnet, ( $\square$ ) Farm with angling; ( $\Delta$ ) Farm with gillnet. $\mathrm{C}$ and D) Loadings plots from PLS-LDA. The first component (C1) was described by $64.65 \%$, the second component (C2) by $17.90 \%$, and the third component (C3) by $9.79 \%$ of the variations.

Figure 5. PLS-LDA performed on ${ }^{1} \mathrm{H}$ NMR spectra from muscle tissues of wild saithe (Pollachius virens) using the proximity to the farm as classification criteria. A and B) Scores plots from PLS- 
421 LDA. ( $\square$ ) Control with angling; ( $\mathbf{\Delta}$ ) Control with gillnet, ( $\square$ ) Farm with angling; ( $\Delta$ ) Farm with 422 gillnet. $\mathrm{C}$ and D) Loadings plots from PLS-LDA. The first component (C1) was described by $42380.43 \%$, the second component $(\mathrm{C} 2)$ by $6.61 \%$, and the third component $(\mathrm{C} 3)$ by $3.77 \%$ of the 424 variations.

425 Figure 6. PLS-LDA performed on ${ }^{1} \mathrm{H}$ NMR spectra from muscle tissues of wild saithe (Pollachius 426 virens) using the fishing method as classification criteria. A and B) Scores plots from PLS-LDA. 427 ( $\square$ ) Control with angling; ( $\mathbf{\Delta})$ Control with gillnet, $(\square)$ Farm with angling; $(\Delta)$ Farm with gillnet. $428 \mathrm{C}$ and D) Loadings plots from PLS-LDA. The first component (C1) was described by $34.29 \%$, the 429 second component (C2) by $19.41 \%$, and the third component (C3) by $19.27 \%$ of the variations. 

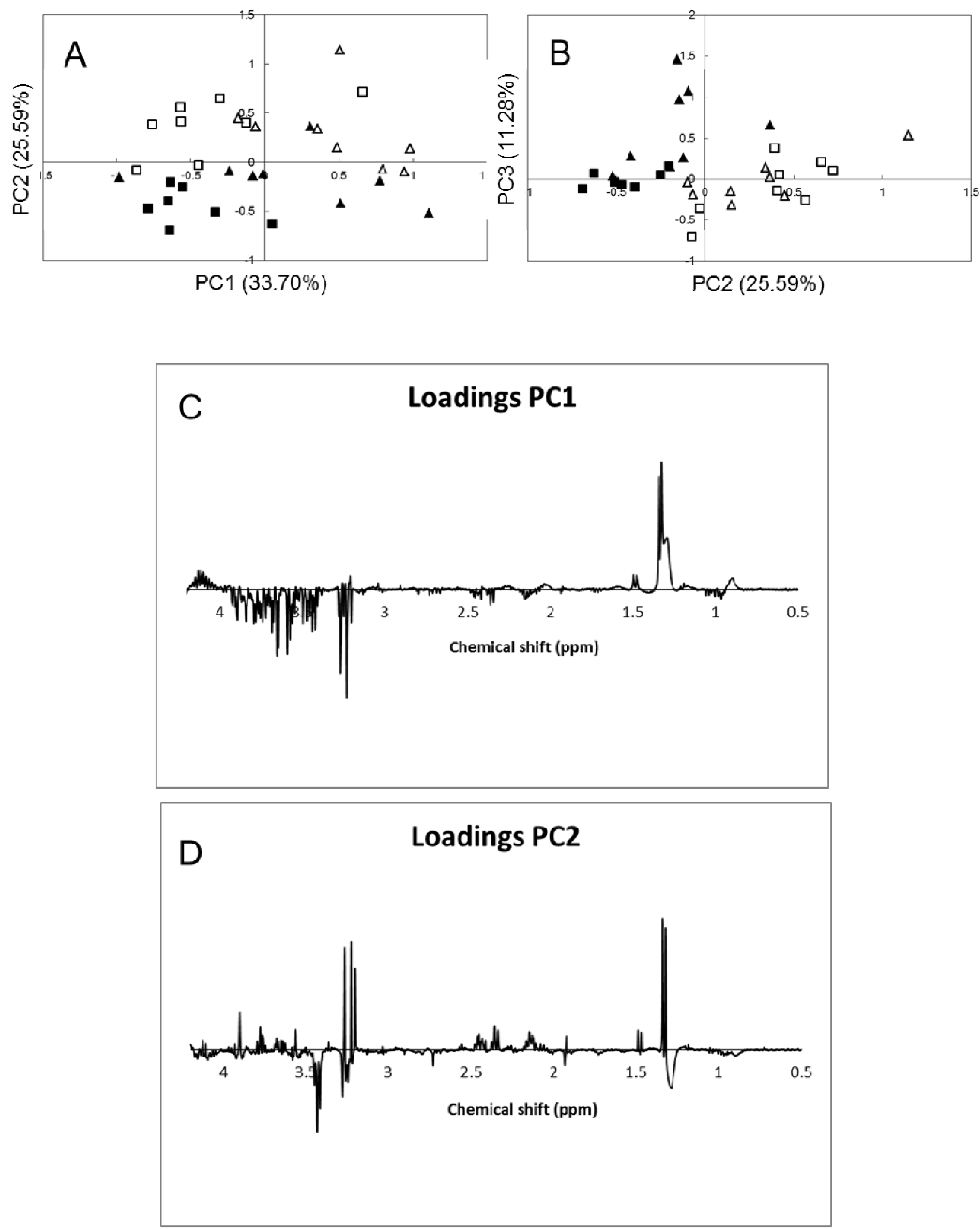

Figure 1. 

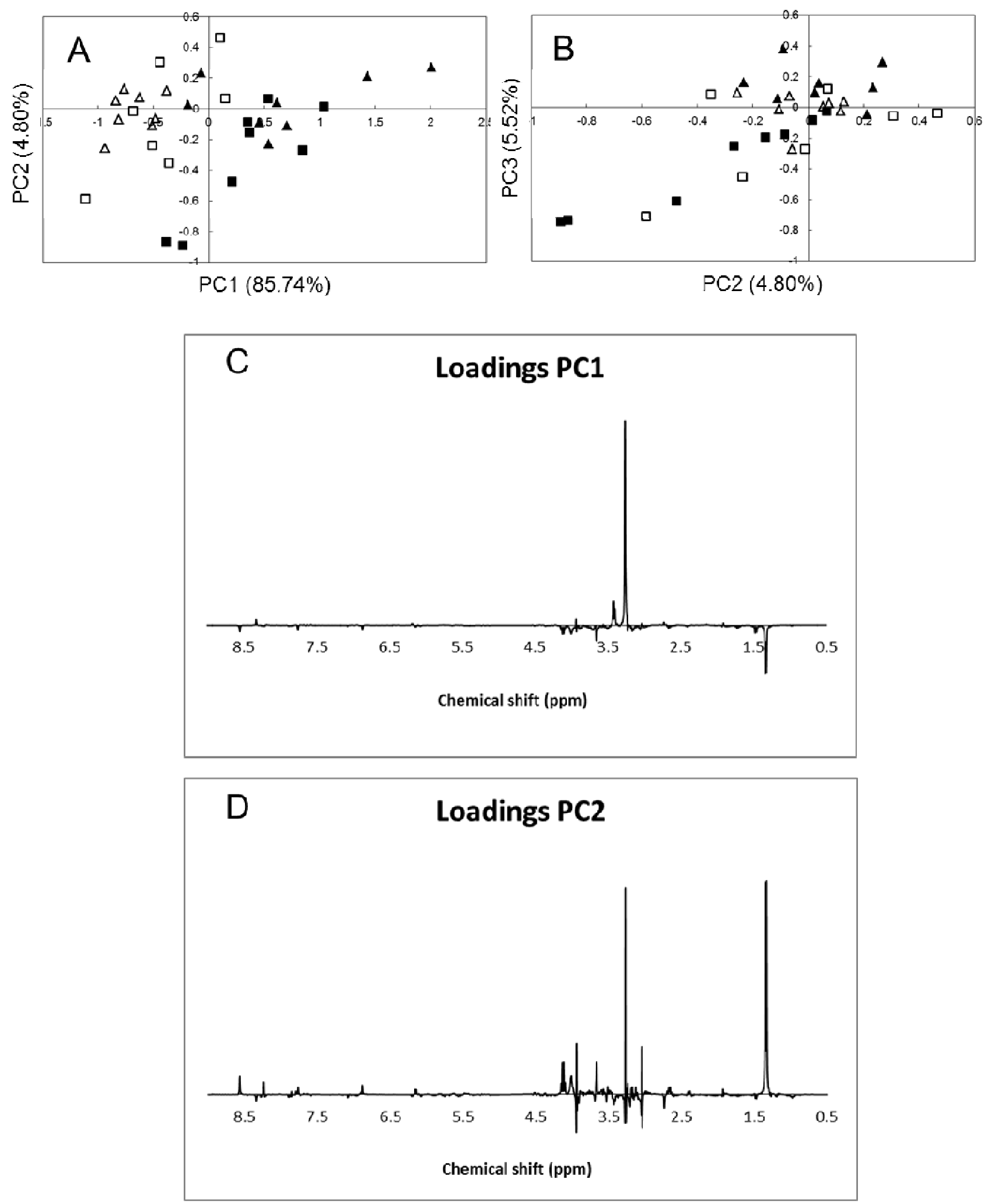

Figure 2. 

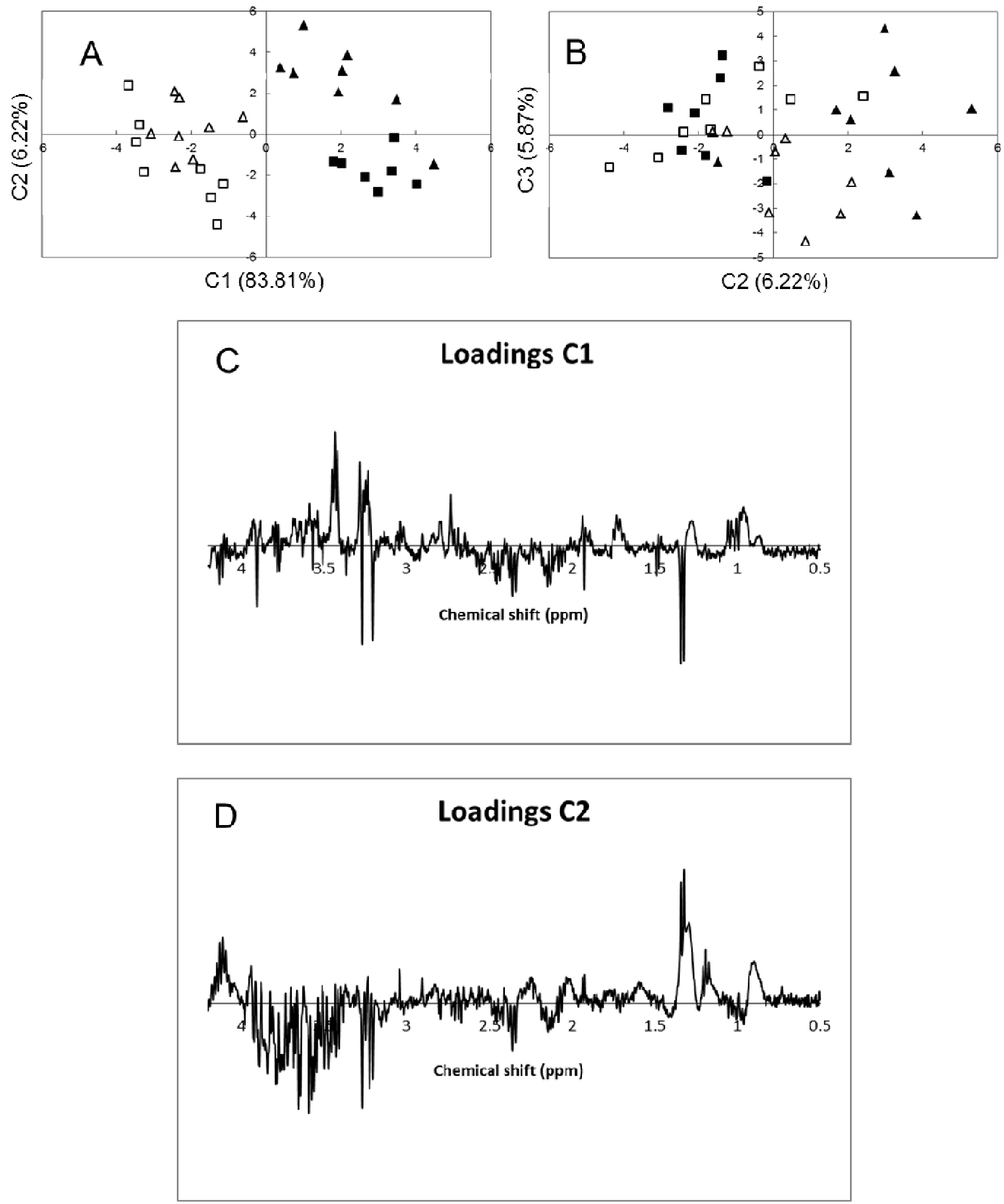

Figure 3. 

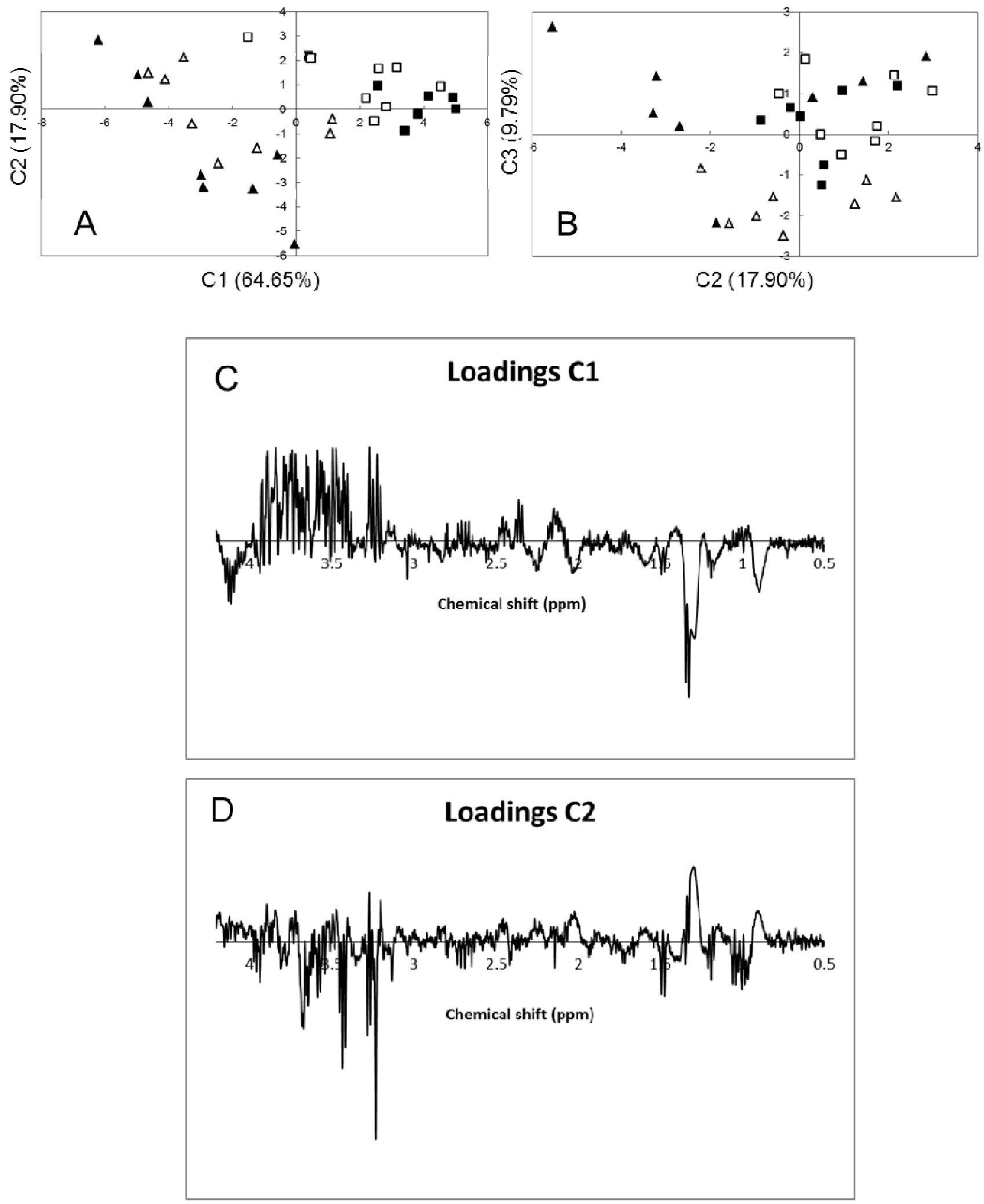

Figure 4. 

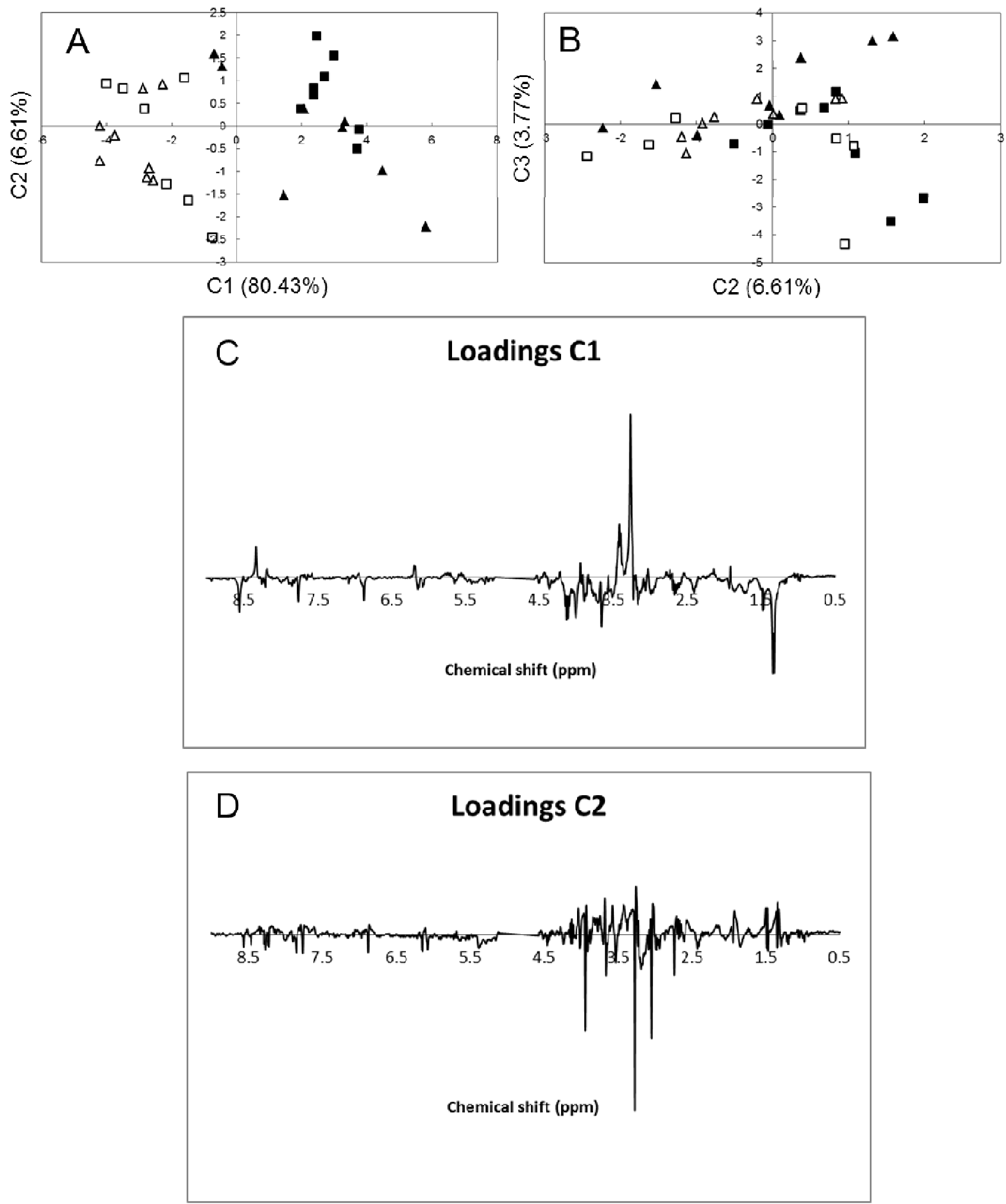

Figure 5. 

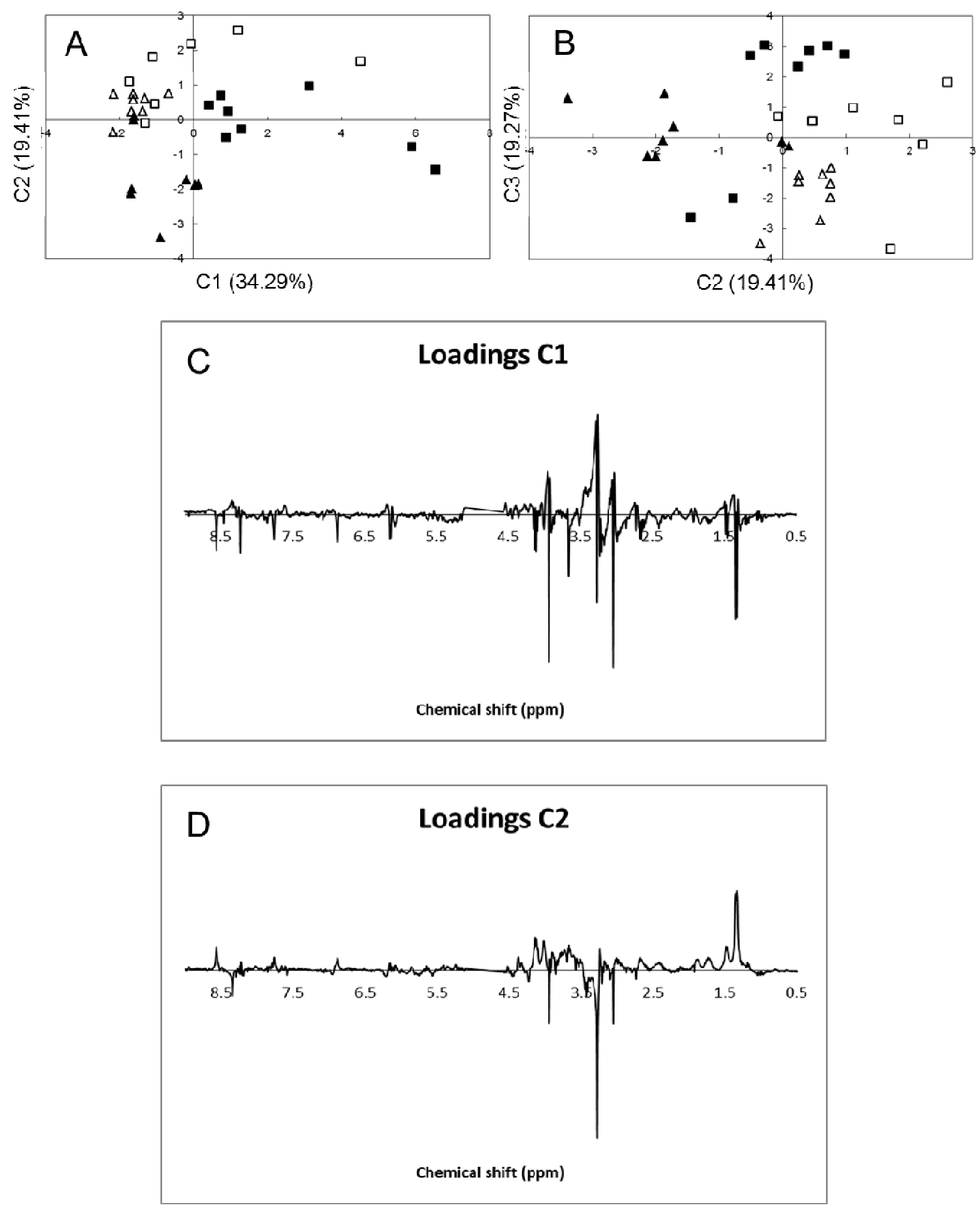

Figure 6. 


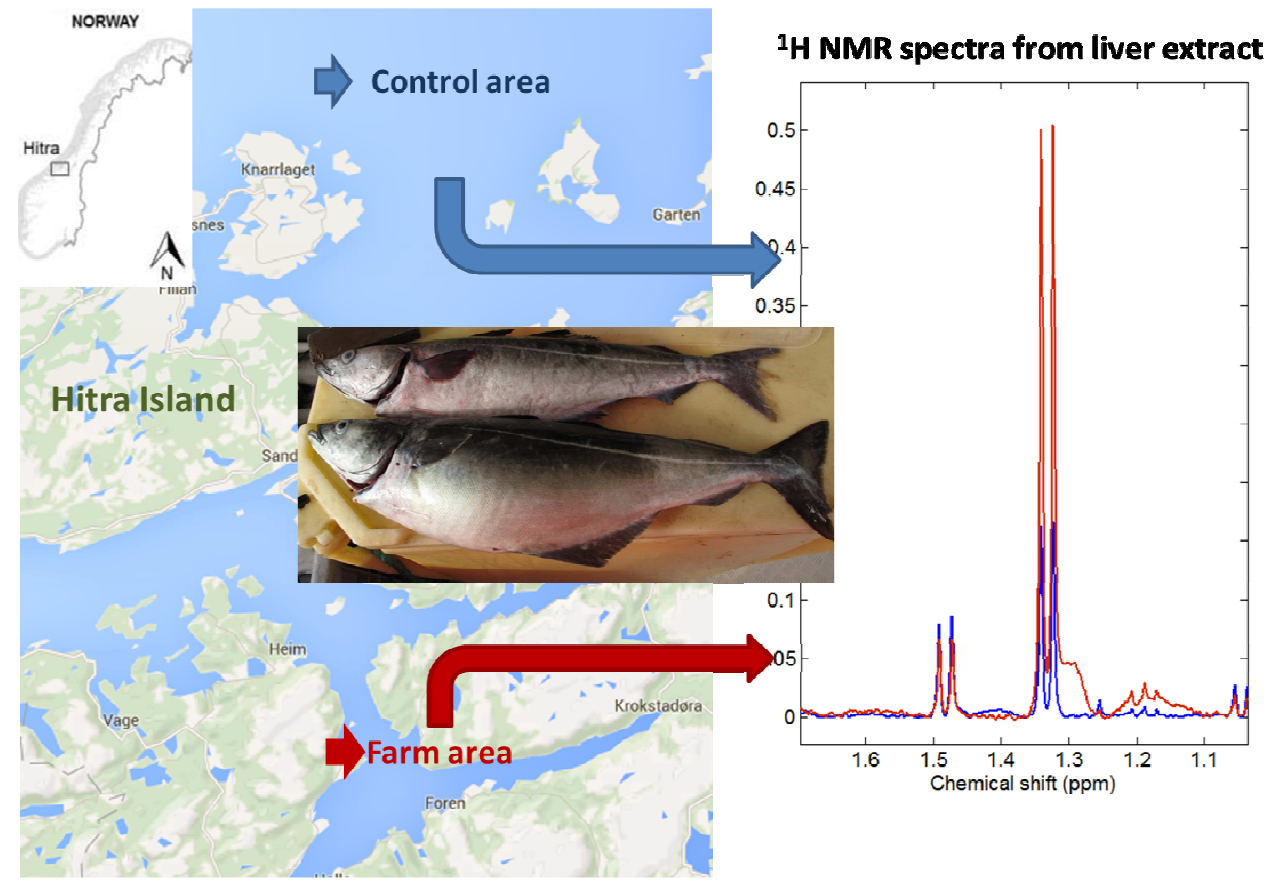

TOC Graphic. 